very. small or none. After many intravenous injections of this preparation the plasma gold concentration and excretion of gold are small and similar to the values usually observed following oral or intramuscular administration. These results are due to quick phagocytosis of the colloidal gold salt by reticulo-endothelial cells.

\title{
REFERENCES
}

1. Freyberg, R. H., Block, W. D., and Levey, S.: " Metabolism, Toxicity and Manner of Action of Gold Compounds used in the Treatment of Arthritis. I. Human Plasma and Synovial Fluid Concentration and Urinary Excretion of Gold during and following Treatment with Gold Sodium Thiomalate, Gold Sodium Thiosulphate and Colloidal Gold Sulphide." J. Clin. Investigation, 1941, 20, 401. (See Annals Rheum. Dis., Vol. II., No. 4, p. 279.)

2. Block, W. D., and Buchanan, O. H.: "The Micro-determination of Gold in Biological Fluids." $J$. Biol. Chem., 1940, 136, 379.

3. Block, W. D., and Buchanan, O. H.: "The Micro-determination of Gold in Tissues and Excreta." To be published.

4. Block, W. D., Buchanan, O. H., and Freybere, R. H.: "Metabolism, Toxicity and Manner of Action of Gold Compounds in the Treatment of Arthritis. II. A Comparative Study of the Distribution and Excretion of Gold following the Intramuscular Injection of Five Different Gold Compounds." J. Pharm. Exptl. Therap., 1941, 73, 200.

5. Unpublished data.

6. Freyberg, R. H., Block, W. D., and Buchanan, O. H.: " Metabolism, Toxicity and Manner of Action of Gold Compounds used in the Treatment of Arthritis. IV. Histologic Changes in Rats effected by Gold Sodium Thiomalate, Gold Sodium Thiosulphate, Colloidal Gold, Colloidal Gold Sulphide and Sodium Succinimido Aurate." To be published.

\section{RESISTANCE IN RHEUMATISM}

\section{BY WILLIAM HUGHES}

CURRENT conception of the mechanism of a disease such as rheumatism postulates the existence of an infective agent which "acts on" or "attacks" the tissues and "produces" a lesion. Certain factors such as age, sex, the presence of septic foci, glandular dysfunction, etc., contribute by lowering the "resistance." In this vague concept all the terms in inverted commas are capable of more than one interpretation, but the one which has caused most confusion in the study of rheumatism is "resistance." This term has been stretched to accommodate the most contradictory hypotheses in the rtiology of the disease, and some promising methods of treatment have been emasculated 
to conform to the hypothetical requirements of " resistance." It is used in immunology to describe part of the complicated dynamic reaction of the host to the infective agent. In the study of the comparatively simple inflammations of experimental pathology it has a circumscribed technical significance. Once it is translated into clinical medicine this definition is lost and confusion results. In Koch's phenomenon, for example, the intense inflammation and necrosis following the second injection of tubercle bacilli is regarded by the immunologist as a sign of high resistance, even though he knows the guinea-pig is suffering from a fatal disease and will certainly die in a short time. In man an injection of tuberculin is followed by a vigorous local reaction-a lesion of a kind-in a previously infected subject. But the reaction is considerably modified or may be completely repressed, as noted originally by von Pirquet $(1911),(a)$ if the subject is very ill, $(b)$ is suffering from some forms of intercurrent disease (e.g., measles), or (c) is pregnant (Nobécourt and Paraf, 1920).

It seems hardly necessary to point out that in this particular instance the absence of the tuberculin reaction in the pregnant woman or debilitated subject is due to lowered resistance. But few clinicians can envisage the possibility of lowered resistance abolishing a lesion. When Hench (1933A) made the extremely interesting discovery that the lesion of rheumatism disappeared during pregnancy, the significance of the part played by lowered resistance in achieving this phenomenon passed unnoticed. So inflexible are the $a$ priori demands of increased resistance that the most roundabout and far-fetched mechanisms were invented to account for theoresults on orthodox lines. Resistance to the clinician with his mind firmly fixed on the outcome of the disease is really a measure of his patient's capacity to survive. The severity of the disease depends on the magnitude of the lesion, and it is difficult to accept the possibility of a high resistance increasing the amount of lesion and, consequently, disease, and a low resistance diminishing the lesion and bringing about temporary or permanent cure.

Still (1897) recorded three cases of juvenile rheumatoid arthritis which showed remarkable improvement after measles, scarlet fever and catarrhal jaundice respectively. In 1903 Wishart reported four cases of chronic rheumatism whose symptoms disappeared with the onset of jaundice. Hench (1933B) 
rediscovered this phenomenon of repression of rheumatic lesions by jaundice. Following Wishart's suggestion that the excess of circulating bile was the curative principle, Hench and other American physicians (Hench, 1938; Thompson and Wyatt, 1938; Sidel, 1938; Rawls, 1938) made an extensive investigation into the therapeutic possibilities of bile salts and pigments without success. The possibility that improvement might be due to the disease associated with jaundice rather than the jaundice itself was not explored. Here again certain immunological data have not been assimilated. Pearce (1928) has published a series of experiments showing the effect of implanting vaccinia virus and Sp. pallida simultaneously in the testicle of a rabbit. Briefly, the evolution of the syphilitic lesions was always delayed. In a controlled series the delay in appearance of the primary lesion amounted to $40 \cdot 1$ days. This is a long time in the life of a rabbit. Many such instances showing the effect one disease can have on' the lesions of another have been recorded in clinical medicine; but here the suppression of lesions is usually referred to as temporary cure. Apart from the instance quoted above the best clinical illustrations are seen in leprosy, where the phenomenon is quite common. Muir (1927) considered that kala-azar could produce a real cure in certain stages of leprosy, and noted that many diseases including enteric fever, dysentery and malaria can produce temporary flattening out of the lesions. He notes (1934) that pregnancy and practically any form of debility will inhibit the leprolin reaction-the counterpart of the tuberculin reaction in tuberculous subjects. The effect of malaria on the lesions of general paralysis provides another good clinical example of this phenomenon.

In connection with jaundice some further significant observations were made by Hench (1938). He noted that the symptoms frequently cleared up in the pre-icteric stage; which shifts the emphasis from the bile pigments to the antecedent debility. The origin of the jaundice was immaterial. There was a "zone of therapeutic effectiveness "- that is, the more intense the jaundice the more likely were the lesions to recede. Atophan (cincophen) jaundice with a 46 per cent. mortality (Palmer and Woodall, 1936) was extremely effective, which, as we shall see, parallels the findings in gold therapy where "toxic cases" do best. Here, then, is a large body of clinical and immunological evidence going to show that the lesions of rheumatism and some 
other diseases can be modified or repressed by agents which lower resistance.

A brief reference to the measures which immunologists have used to suppress the reaction of anaphylaxis will help to throw some further light on the mechanism by which certain drastic treatments bring about cure in rheumatism. We find the most diverse agents credited with the power of inhibiting the development of anaphylaxis. Hill and Martin (1932), in a valuable review of the subject, give a long list of agents which have been reported as effective in inhibiting the reaction. Included in the list we find such diverse agents as milk, peptone, colloids, dyes, surgical operations, vitamin deficiency, starvation, pregnancy and intercurrent disease, etc. There is more than a superficial resemblance between these agents and the agents which, as we shall see later, have been described as little short of miraculous in the treatment of rheumatism. It would be just to conclude that practically any material interference will inhibit the development of a fatal reaction in anaphylaxis. Hill and Martin observe that even sodium chloride, if the dose is " pushed," will inhibit the reaction, but they point out that sickness and death frequently result from the therapeusis. It is difficult to express all that is implied by such an observation. It means that to initiate this reaction which may entail injury to tissues, or even its own death, the body must be in a reasonably good state of health and free from undue material interference when the exciting stimulus is applied. This presents no difficulty to immunologists, who regard the anaphylactic reaction as a manifestation of high resistance and are prepared to see it inhibited by agents which lower the resistance. The clinician finds it difficult to assimilate such a conclusion in his conception of the mechanism and treatment of rheumatism. Using similar or identical agents in the treatment of rheumatism, he has been at infinite pains to show-often by verbal subterfuge-how they increase rather than diminish the resistance and so bring about cure.

Generally speaking, measures which increase the resistancesanatorium regime, eradication of small septic foci-have not been followed by rapid or spectacular success in rheumatism. It has been said that the path of therapeutics in this disease is strewn with the ghosts of rational treatments-the latter always based on efforts to increase resistance. At the same time, intuition, accident and empirical observation have introduced us 
to many agents which have brought about spectacular cures. A selection from the literature is set out on p. 94 in a classification intended to bring out the relation between the debility associated with each agent and its curative effect.

A few words of comment on the reliability of the data for the classification are necessary. The observations on the effects of pregnancy and jaundice and infectious disease can be accepted without difficulty, chiefly because they are made without the prejudice that goes with the introduction of a new form of treatment. With regard to the various forms of treatment one should make allowance in each case for prejudice on the part of the author. I have, therefore, given authority for every treatment which is not adequately described in the average textbook.

It will be seen from the classification that the more toxic or debilitating the agent the better is the result. Commenting on the effects of jaundice, Hench noted that it brought about remission of symptoms with more rapidity and certainty than any other physiological change or pharmacological agent known. Hench (1933) first noted this repression of rheumatic lesions in cases of jaundice due to atophan poisoning.

Lagèze (1939), reporting a fatal case of stomatitis and jaundice following gold therapy, found that the rheumatism cleared up before death. Hartfall and Garland (1935) in their original series of cases treated with gold had a 3 per cent. mortality. Ellman and Lawrence (1938) report favourably on gold therapy. They had one death from agranulocytosis besides the usual series of toxic reactions in a series of 16 cases. Phillips (1936), one of the few Americans to try gold, had to give it up on account of the number of toxic reactions. He confesses he did not feel competent to handle the drug to the advantage of the patient. Incidentally, it is constantly reported in the literature that " toxic" cases in gold do very well (Crosby, 1936; Tegner, 1937).

We should expect that any drug given in excessive doses would produce good results in a percentage of cases. In leprosy $\frac{1}{2}$ ounce of potassium iodide daily will repress the lesions; in anaphylaxis excessive dosage of sodium chloride will prevent the reaction if the animal survives. It is interesting to note that this type of therapy is represented in rheumatism by giving excessive doses of vitamin D-probably the only vitamin which lends itself to such a purpose. Dreyer and Reed (1936) had to 


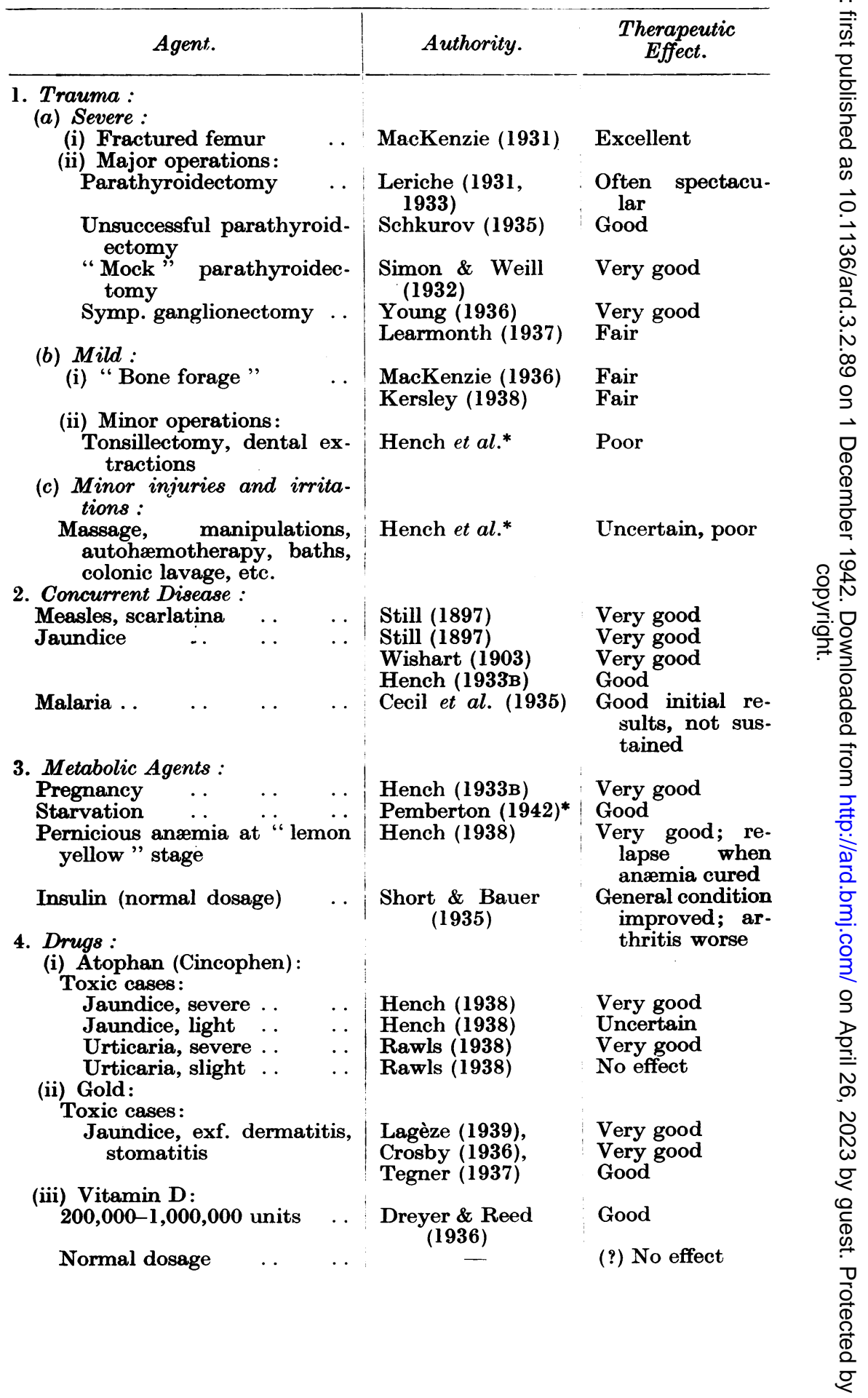


CLASSIFICATION-Continued

\begin{tabular}{|c|c|c|c|}
\hline Agent. & & Authority. & $\begin{array}{c}\text { Therapeutic } \\
\text { Effect. }\end{array}$ \\
\hline $\begin{array}{l}\text { 5. Biological Agents : } \\
\text { (i) Diathermy fever .. }\end{array}$ & $\cdots$ & $\begin{array}{c}\text { Short \& Bauer } \\
(\mathbf{1 9 3 5 )}\end{array}$ & $\begin{array}{l}\text { Good initial re- } \\
\text { sults, not sus- } \\
\text { tained }\end{array}$ \\
\hline $\begin{array}{l}\text { (ii) Intravenous vaccines: } \\
\text { (a) T.A.B. } \\
\text { (b) Streptococcal } \\
\text { (iii) Subcutaneous vaccines }\end{array}$ & $\begin{array}{l}\ldots \\
\cdots \\
\ldots\end{array}$ & $\begin{array}{l}\text { Hench }(1941)^{*} \\
\text { Wetherby }(1941)\end{array}$ & $\begin{array}{l}\text { Fair } \\
\text { Good } \\
\text { Useless }\end{array}$ \\
\hline
\end{tabular}

* Every year Hench and his colleagues publish a lengthy and informative review of chronic rheumatic diseases. The most recent is the Seventh Rhermatiom Review (Hench, Bauer, Dawson, Hall, Holbrook, Key, McEwen, 1941). Mention is made of all the agents described in one or other of these reviews.

give up to $1,000,000$ units daily to achieve results. This is five times the maximum safe dose according to Park (1938).

There is a gradual decline in therapeutic effect as the toxicity of the agent decreases. Atophan jaundice with a 46 per cent. mortality ranks high as a therapeutic agent; raising the resistance by means of sanatorium regime gives poor results.

The effects of trauma on the rheumatic lesion show a similar trend. The severe trauma of a fractured femur was so effective that it inspired MacKenzie to develop what has now become known as " bone forage" (MacKenzie, 1936; Kersley, 1938). In this operation a piece of bone is drilled away. Possibly with refinement of technique the trauma has been attenuated and successes are not now reported so often in the literature.

Leriche $(1931,1933)$ postulated a disordered calcium metabolism in rheumatism, and by surgical assaults on the affected bone, parathyroids and local sympathetic ganglia, achieved results which he described in some cases as miraculous, but he confesses that they were not permanent. The rational basis of his success was exploded by Simon and Weill (1932) when they found a "mock" operation on the parathyroid did just as well. Again, Schkurov (1935), who had good results from operation on the parathyroid in 83 cases, had tissues sectioned after removal at operation. In 23 cases no parathyroid was found. Further, it appears that in cases where ganglionectomy is performed (Young, 1936; Learmonth, 1937) the improvement is not confined to the joints supplied by the ganglia which were removed. 
As we descend from these major traumata to minor operations on septic foci in the tonsils, sinuses, and teeth sockets, there is a decline in the percentage of successes.

I have classified massage under the heading of trauma. Many of the manipulations and vigorous forms of massage probably depend for their effect on a certain amount of tissue destruction. Wright (1938) has drawn attention to this possibility.

The results with artificial fever, however induced, may be spectacular at the beginning but are rarely permanent. Short and Bauer (1935), using diathermy, treated 25 cases. It is interesting to note that one of the 5 cases showing sustained improvement was that of a woman who became pregnant during the period of amelioration. Presenting a neat contrast with this is the case reported of a man who put on 9 lbs. in weight under the influence of insulin administration. At the end of ten months his general condition was excellent but his arthritis was much worse.

Pemberton (1942) mentions that cures have followed starvation diets of the "Hollywood" type, although he does not approve of them. He considers that there is alimentary dysfunction in rheumatism which should be treated by withholding fat. Giving a high protein and carbohydrate, low-calorie diet, he claims to be able to increase the resistance and bring about improvement.

The classification emphasises the relationship between major debility and high therapeutic efficiency. Atophan, gold and excessive vitamin $\mathbf{D}$ have all been condemned as dangerous remedies and lauded for their beneficial effects. It is impossible to escape from the conclusion that a certain amount of debility is necessary if we are going to achieve results. There is plenty of scope, however, for ingenuity in devising safe measures to lower the resistance below the level at which lesions can occur. Trauma locally applied, for example, may have interesting possibilities. Osteotomy (bone forage) seems to have produced fair results. Massage and various forms of local interference continue to be used in treatment. In this respect it is interesting to note that as long as Pearce injected vaccinia virus and $T$. pallidum simultaneously into the same testicle the syphilitic lesions were repressed. When the vaccinia was inoculated at a distant site no such effect ensued. Similarly, when Ledingham 
(1927) injected Indian ink and vaccinia virus into the skin of a rabbit no lesion occurred. A previous streptococcal infection had the same effect. But if the virus seeped out beyond the limits of the prepared area vesicles occurred. Possibly the same amount of trauma inflicted locally would be more efficacious than when applied at a distance in rheumatism. Refinement of technique must aim at reducing the mortality while retaining the trauma.

The following is an example of a method of treating gonococcal rheumatism evolved to meet an emergency. In Nigeria in presulphonamide days gonococcal rheumatism was extremely common and difficult to cure. To treat the patient at rest for long periods constituted a special problem in hospital administration which disappeared after the introduction of sulphapyridine. Towards the end of 1941, however, our stocks of this drug became very low, and we had to conserve supplies for cases of pneumonia. In these circumstances I used a method of treatment introduced by Bryant and Fairman (1939) in the Sudan during an epidemic of cerebrospinal meningitis. They injected intramuscularly a saline suspension of M. \& B. 693 tablets. We injected 10 c.c. of the suspension containing 1 gramme sulphapyridine into the buttocks. This is followed by fever and a large, diffuse and somewhat painful swelling of the buttock with almost simultaneous analgesia in the affected joints. In 14 cases treated the results were excellent and in 1 case spectacular. This was a policeman who had been treated by small and irregular doses by mouth for six weeks. Both wrist and knee joints were swollen and painful, and muscular atrophy was already obvious. He was sent up for invaliding. After three injections on alternate days the swellings had disappeared. The patient was discharged after ten days in hospital, and was back on duty within three weeks. Used in this fashion we were able to get as much effect with 3 or 4 grammes of sulphapyridine as might be expected from 20 to 50 grammes orally. Sulphapyridine is generally so effective by mouth that this is not a treatment which $I$ particularly recommend, except in such circumstances as have been described. It is quoted merely to illustrate the therapeutic possibilities of attacking the lesion as well as the infection. 


\section{Discussion}

The orthodox teaching in regard to resistance is based largely on Metchnikoff's theory in which pride of place is given to the cellular exudate in restraining infection. In simple experimental lesions it seems obvious enough that these cells exercise a useful function by phagocytosing organisms. The more cells there are in such a lesion the higher the resistance to infection; but, clinically, the bigger the lesion, the more severe the disease. In the complicated circumstances of disease, therefore, there is no simple solution to the problem of the various exudates, the space they occupy and the function they serve. Less and less reliance is being placed on the lesion as a barrier against the spread of infection. After much work on the subject Rich (1937) and his colleagues have been led to the conclusion that the lesion in tuberculosis, while it may have been designed for a useful purpose, never fulfils such a purpose in the actual circumstances of disease. Consequently they have tried to get rid of it by desensitisation. Clinically, the treatment of general paralysis by shock therapy provides the most successful example of lowering resistance in order to get rid of the lesion. Here the fate of the infection is ignored.

Unfortunately, the clinical ideal of immunity without lesions cannot always be realised. In leprosy, as in rheumatism and anaphylaxis, a recession of lesions can be achieved by practically any form of debility. But it would seem that the lesion in leprosy has some restraining influence on the infection because the disease usually recurs in a more widespread form after a drastic remedy has ceased to operate. The wave of bitter disappointment following the failure of each spectacular " cure " provides a warning against the facile assumption that resistance can always be lowered with impunity.

But if lowering resistance as a method of treatment has its failures in practice it does not necessarily follow that raising resistance is always safe. Some years ago an anti-streptococcal serum was introduced for the treatment of puerperal sepsis. In spite of-or, should we say, because of - the fact that it was a potent serum, it doubled the mortality of the cases treated (Colebrook, 1935). Convalescent (immune) serum has had an extensive trial in the treatment of poliomyelitis. Where controls were established results suggest that the serum is certainly 
useless and probably harmful (Faber, 1941). In Roshenholtz' (1938) review there is one adequately controlled series which suggests that convalescent serum quadruples the mortality in this disease. The treatment of the same disease provides an interesting example of the effects of vigorous interference with the course of the disease. Orthodox treatment enjoins rest and often splints in the early stage and with remedial exercises later. Sister Kenny, who has established a world-wide reputation for her methods of treating this disease, advocates movements from the very first day. This is not the place to enter into the controversy about the value of the Kenny treatment, but it can be said that the treatment has stood up well to criticism and, on balance, it appears a little superior to that based on rest and increased resistance. Altogether it appears in this disease that measures directed towards increasing the resistance-immune serum and rest-are a little inferior to those which might reasonably be held to lower the resistance.

There is a sound rational basis for augmentation of resistance before infection is introduced. In the urgent circumstances of established disease, however, measures designed to increase the resistance- of which the lesion itself is an expression-are open to grave objections. Theoretically, it is not really surprising that such measures have had so little success. The main purpose of this article is to show that the use of trauma or debility to lower the resistance in rheumatism is a rational procedure. This hypothesis explains the empirical successes of the most diverse and often fantastic agents in rheumatism. There is one factor common to all successful remedies-we can describe it as shock, or trauma, or debility. Refinement of technique must be directed not so much towards attenuating the shock as to the discovery of the minimum amount of debility necessary for repression of the lesion.

It might be considered a disadvantage that the infective agent has not yet been identified in this disease. But whatever it is there is as yet no evidence that it propagates when the lesions are repressed. So long as there is no mortality associated with such measures we can apply them for the purpose of study with a good conscience, which after all is not the case in leprosy or general paralysis. Indeed, one could almost hope that the rheumatic infection would propagate during debility as this might lead to its early identification. 


\section{SUMmaRY}

The lesion in rheumatism is an expression of high resistance. It is a complicated and dynamic affair which can be simultaneously the source of disease and the basis of cellular resistance. It can be repressed by various debilitating agents-trauma, concurrent disease, disturbance of metabolism, dangerous drugs. In such circumstances there is no evidence that the infective agent, whatever it may be, propagates during the time the lesion is in abeyance.

Although the lesion is purposeful we cannot say that in rheumatism it fulfils any useful function. It is suggested, therefore, that in treatment we can ignore the infection, regard the lesion as physiologically unnecessary, and consciously adopt measures to lower the resistance.

The exploitation of this hypothesis should open up new and profitable fields of research in therapeutics.

A practical application in gonococcal rheumatism has been described.

\section{REFERENCES}

Bryant, J., and Fatrman, H. D. (1939): Lancet, ii, 923.

CeCII, R. L., Friess, C., Nrcholrs, E. E., Thomas, W. K. T. (1935): J. Amer. Med. Ass., 117, 275.

Colebrook, L. (1935): Lancet, ii, 1085.

CrosBy, G. J. V. (1936): Lancet, ii, 1463.

DreYer, I., and REED, C. I. (1935): Arch. Phys. Ther., 16, 537.

Eluman, P., and Lawrence, J. S. (1938): Rep. Chron. Rheum. Dis., 3, 63.

Faber, H. K. (1941): J. Amer. Med. As8., 117, 275.

Hartyall, S. J., and Garland, H. G. (1935): Lancet, ii, 8.

Hench, P. S. (1933A): Proc. Staff Mayo Clin., 8, 161.

HENCH, P. S. (1933в): ibid., 8, 430.

HENCH, P. S. (1938): Arch. Int. Med., 61, 451.

Hench, P. S., Baugr, W., Dawson, M. H., Hall, F., Holbrook, W. P., KEY, J. A., McEwEN, C. (1941): Ann. Int. Med., 14, 1383, 1631.

Hun, J. A., and Martin, L. (1932): Medicine, 11, 141.

Kersley, G. D. (1938): Rep. Chron. Rheum. Dis., 4, 68.

LaGìze, P. (1939) : Presse Méd., 47, 864.

Learmonth, J. R. (1937): Rep. Chron. Rheum. Dis., 3, 8.

Lednaham, J. C. G., (1927): Brit. J. Exp. Path., 8, 12.

LERTCHE, R., and JUNG, A. (1931): Lyon. Chir., 28, 408.

Leriche, R., and Jung, A. (1933): Presse Méd., 41, 66.

MacKenzie, J. F. (1931): Med. J. Austral., 1, 441.

MAdKranzir, J. F. (1936): Brit. Med. J., i, 306.

MUIR, E. (1927): Ind. J. Med. Res., 15, 497.

MUIR, E. (1934): Ind. Med. Gaz., 69, 495.

Nobícourt, P., and Parat, F. (1920), Presse Méd., 28, 133.

Palmer, W. L., and Woodall, P. S. (1936): J. Amer. Med. Ass., 107, 760. 
PARK, E. A. (1938): ibid., 111, 1179.

Pearce, L. (1928): J. Exp. Med., 48, 125, 363.

Pemberton, R., and Scull, C. W. (1942): Ann. Rheum. Dis., 3, 42.

Phinurs, R. T. (1936): New Eng. J. Med., 214, 114 .

von Pirquet, C. E. (1911): Ann. Int. Med., 7, 259, 283.

RAwLs, W. B. (1938): Arch. Int. Med., 61, 495.

RICH, A. R. (1936): Arch. Path., 22, 228.

RoshenHOLtz, B. (1938): Minnesota Md., 21, 115.

SchkUROV, B. (1935): J. Bone and Joint Surg., 17, 571.

SHORT, C. L., and BAUER, W. (1935): J. Amer. Med. Ass., 104, 2165.

Sider, N. (1938): Arch. Int. Med., 61, 495.

Srmon, R., and WerLl, T. (1932): Presse Méd., 40, 412.

StIIL, G. F. (1897): Med. Chir. Trans., 80, 48.

Tegner, W. (1937): Rep. Chron. Rheum. Dis., 3, 63.

Thompson, H. E., and WyatT, B. L. (1938): Arch. Int. Med., 61, 481.

WETHERBY, B. (1941): Ann. Int. Med., 14, 1849.

Wishart, J. (1903): Brit. Med. J., i, 252.

Wright, S. (1938): Proc. R. Soc. Med., 32, 651.

Young, A. (1936): Brit. Med. J., ii, 375.

\title{
CULTURAL STUDIES ON RHEUMATOID ARTHRITIS AND RHEUMATIC FEVER
}

\author{
BY D. MURRAY ANGEVINE, SYDNEY ROTHBARD, \\ RUSSELL L. CECIL \\ Depts. of Pathology and Medicine, Cornell University Medical College, \\ New York City
}

The literature on cultural studies in rheumatoid arthritis and rheumatic fever is so familiar to those interested in these diseases that no detailed description will be given; however, a few studies will be mentioned.

Cecil, Nicholls, and Stainsby ${ }^{1}$ recovered streptococci from the blood and joints of the majority of their patients with rheumatoid arthritis, and Gray and Gowen ${ }^{2}$ confirmed their observations. Dawson, Olmstead and Boots ${ }^{3}$ were unable to do so. McEwen, Bunim and Alexander recovered streptococci from the blood of 21 per cent. of their patients with atrophic arthritis and from 6 per cent. of the controls. Margolis and Dorsey ${ }^{5}$ recovered streptococci from the blood and tissues from some of their cases and attached significance to the presence of these bacteria. Collins ${ }^{6}$ obtained negative cultures from the synovial fluid of a large number of cases of atrophic arthritis. Blair and Hallman? were unable to isolate any significant organism from the synovial fluid or tissue of similar cases. Sabin ${ }^{8}$, Findlay, Mackenzie and 